\title{
The Frequency of Smoking and Common Factors Leading to Continuation of Smoking among Health Care Providers in Tertiary Care Hospitals of Karachi
}

\author{
Muhammad Shahzeb Khan ${ }^{1}$, Faizan Imran Bawany ${ }^{1}$, Muhammad Umer Ahmed ${ }^{2}$, Mehwish Hussain ${ }^{1}$, Noreen \\ Maqbool Bukhari ${ }^{3}$, Nighat Nisar ${ }^{3}$, Maham Khan ${ }^{1}$, Ahmed Raheem ${ }^{4} \&$ Mohammad Hussham Arshad $^{4}$ \\ ${ }^{1}$ Dow Medical College, Dow University of Health Sciences, Karachi, Pakistan \\ ${ }^{2}$ Ziauddin Medical University, Karachi, Pakistan \\ ${ }^{3}$ Community Medicine Department, Dow University of Health Sciences, Karachi, Pakistan \\ ${ }^{4}$ Aga Khan University Hospital, Karachi, Pakistan \\ Correspondence: Muhammad Shahzeb Khan, 109/2 Khayabane Amir Khusro Phase 6 DHA, Karachi, Pakistan. \\ Tel: 0321-2066743. E-mail: shahzebkhan@gmail.com
}

\author{
Received: December 30, 2013 Accepted: January 24, 2014 Online Published: March 30, 2014 \\ doi:10.5539/gjhs.v6n3p227 URL: http://dx.doi.org/10.5539/gjhs.v6n3p227
}

\begin{abstract}
Background: The primary objective of the study was to find out the frequency of tobacco smoking among health care providers in tertiary care hospitals of Karachi. The secondary objective was to identify the common factors responsible for the continuation of smoking.

Method: This cross sectional study was conducted in the wards and out-patient departments of three selected tertiary hospitals of Karachi. A total of 180 health care providers were enrolled in the study using proportionate stratified sampling. Postgraduate students, house officers and trainees were excluded from the study. Data were collected from randomly selected health care providers using survey methodology. SPSS v. 20.0 was used to enter and analyze the data.
\end{abstract}

Results: Fifty two participants out of 180 were smokers for past one year (28.9\%). Among them, 21 (11.7\%) smoked more than 5 cigarettes per day. Twenty smokers $(11.1 \%)$ were found to smoke due to peer influence. It was found that those who were influenced by their peers were 8.33 times more prone to be addicted to smoking than those who were less influenced. Similarly, the likelihood of addiction increased up to $76.9 \%$ with the lack of incentives.

Conclusion: Our results clearly indicate that a large number of health care providers smoke which should be a serious concern. Hence our health agencies should take immediate action in order to curtail the heaving burden of smoking and its related health consequences.

Keywords: smoking, healthcare providers, tertiary care hospitals, factors

\section{Introduction}

Cigarette smoking is the largest preventable risk factor for morbidity and mortality in developed countries, where at least one in four adults smoke cigarettes (Thomson, Chaudhuri, \& Livingston, 2004). Situation in the developing countries is even worse. It is estimated that by 2030 the developing world is expected to have 7 million deaths annually from tobacco use (Abdullah \& Husten, 2004). Unfortunately, Pakistan is one of those countries where despite escalating knowledge and awareness programs, cigarette smoking is ever rising. With the smoking epidemic, the role of health care providers is most crucial in lowering down the smoking rates among the masses \& thereby preventing many avoidable diseases.

Most ironical fact is that healthcare providers too have tendency to smoke. This is a global issue. Health Care Providers all over the world have been identified to be involved in smoking, at least to some extent. An American study (Serna, Bialuos, Sinha, Yang, \& Wewers, 2010) indicates that in 2006/2007, Licensed Practical Nurses had the highest prevalence of tobacco smoking $(20.55 \%)$ followed by respiratory therapists $(19.28 \%)$. Physicians had a prevalence of $2.31 \%$, dentists (3.01\%), pharmacists (3.25\%), and Registered Nurses (10.73\%). 
The overall prevalence of smoking among health care providers was $9.85 \%$ (Serna et al., 2010). Similarly, a study from China (Yan et al., 2008) identified $20.8 \%$ of health care providers as current smokers. Smoking among physicians was very high $(35.7 \%)$ according to this study and $59.7 \%$ of the respondents believed that inadequate knowledge was responsible for their continuation of smoking.

There are very few local studies addressing this problem. Little work has been done on a large scale to find the prevalence of smoking among health care providers and the significant factor responsible for their continuation of smoking besides its hazardous effects. A recent study from Lahore (Malick et al., 2010) conducted at Mayo hospital found out the frequency of smoking among doctors to be $37.18 \%$ and in paramedical staff to be $35.74 \%$. Most of them initiated smoking due to the influence of friends. Majority of doctors and paramedics found smoking as relaxing/addicting and was the main reason they couldn't quit. Main factors responsible for continuation of smoking were addiction (Doctors 38\%, Paramedics $42 \%$ ), lack of will power (Doctors $21 \%$, Paramedics 27\%) and lack of incentive (Doctors 24\%, Paramedics 12\%). On the other hand, among general practitioners, $36 \%$ were found to be cigarette smokers, who consumed 12.48 cigarettes per day and had 18.76 average years of smoking. Half of them had been smoking for more than 20 years (Nawaz \& Naqvi, 2010).

Physicians who smoke are less likely to advise patients to quit smoking. Also, it is less expected from them to assess patient's will to refrain from smoking (Asfar, Al-Ali, Ward, Vander Weg, \& Maziak, 2011). In addition to all the smoking related health hazards that health care providers are exposed to, they are also not able to counsel their patients effectively. It is evident that if health care providers themselves smoke, they cannot educate masses regarding smoking cessation.

There is a need of a large scale study involving more than one tertiary care hospitals to find out the frequency of smoking among health care providers (both doctors \& paramedics) and to appraise the reasons behind their continuation of smoking despite their medical edification. This study will help to identify factors responsible for continuation of smoking so that recommendations can be made for its cessation among health care providers and thereafter the community. The primary objective of the study was to find out the frequency of tobacco smoking among health care providers in tertiary care hospitals of Karachi. The secondary objective was to identify the common factors responsible for the continuation of smoking among health care providers.

\section{Methods}

This cross sectional study was conducted in wards and out-patient departments of three selected tertiary hospitals of Karachi namely Civil Hospital, PNS Shifa and Liaquat National Hospital. A sample size of 163 was calculated at $95 \%$ confidence interval by keeping the smallest frequency of responsible factors that was lack of incentive among paramedics as $12 \%$ (Malick et al., 2010). So a total of 180 health care providers were enrolled in the study using proportionate stratified sampling.Postgraduate students, house officers and trainees were excluded from the study. Doctors and paramedics (nurses and technicians) of either gender who were working in tertiary care hospitals were only included in the study. However, doctors and paramedics who were working in hospitals where beds were less than 200 were also excluded from the study.

In Karachi there are 110 private and public hospitals in a ratio of 2:1. So 2 private and 1 public hospital were selected to generalize our findings accurately. Proportionate sample was taken from each hospital. Doctors and paramedical staff were listed according to their hospital identity number provided by the hospitals to form sampling frame. Total number of doctors and paramedical staff at civil hospital were 604 and 1850 respectively and their proportionate sample calculated was 32 and 96 respectively. Therefore randomly we selected first doctor and paramedical staff by random number table and moved down the column selecting appropriate numbers that identified 32 doctors and 96 paramedical staff. Similarly for PNS Shifa and Liaquat National Hospital randomly we selected first and moved down until we identified 5 doctors and 16 paramedical staff for PNS Shifa and 6 doctors and 25 paramedical staff for Liaquat National hospital.

After ethical review committee of Dow University of Health Sciences (DUHS) approval, data collection started. Principal investigator explained the nature and purpose of study to all selected participants. Data were collected from randomly selected health care providers using survey methodology until the sample size was achieved. Confounder was managed through randomized selection of subjects. Confidentiality and anonymity was maintained to obtain as frank answers as possible. To avoid non response bias, questionnaire used (Global adult tobacco survey collaborative group, 2011) was not too long and did not take much time to complete. The questionnaire comprised of three parts. Part A was designed to measure socio-demographic data including age, gender, type of health care provider, department, specialty, duration of occupation. Part B was about the smoking status. Part $\mathrm{C}$ determined the socio demographic, environmental and personal factors, which could contribute in the continuation of current smoking among health care providers. The factors that were assessed were influence 
of friend/peer pressure, addiction, lack of will power and lack of incentive which have previously been identified as significantly associated with smoking among health care providers (Yan et al., 2008). The operational definition for these factors was taken as:

Lack of will power: It is the inability to try to quit smoking ever in the past.

Lack of incentive: Lack of due promotions and increments in salary despite putting in efforts.

Influence of friends and peer pressure: If a person spends more than 6hours (25\% of the day) in the company of those friends or colleagues who smoke and if the majority $(>50 \%)$ of his friends are smokers he is influenced by them.

Addiction: A person is addicted if he smokes even at workplace and home and the absence of smoking causes inability to continue routine work.

SPSS v. 20.0 was used to enter and analyze the data. Categorical variables were presented as frequencies with percentages. Mean and standard deviation was computed for continuous variable i.e. age. Chi-Square test of association was used to see effect of demographic variables on factors leading to smoking habits. Odds ratio was computed for estimating the effect within factors. P Value less than 0.05 was considered to show significant effect.

\section{Results}

There were total $116(64.4 \%)$ males and 64 (35.6\%) females. Most of them $(\mathrm{n}=128,71.1 \%)$ were from public university (DUHS). Forty three were doctors, 67 nurses and 70 were technicians. Fifty five percent were working in medicine department. The remaining $45 \%(n=81)$ were employees of surgery department.

Fifty two participants were smokers for the past one year (28.9\%). Among them, 21 (11.7\%) smoked more than 5 cigarettes per day. (Table 1)

Twenty two (12.2\%) participants had more than fifty percent smoker friends. The frequency of participants spending hours with such friends for more than 6 hours was same $(n=22,12.2 \%)$. Though, $20(11.1 \%)$ were found to smoke due to peer influenced as described in our operational definition.

At workplace, $18.9 \%(\mathrm{n}=34)$ participants smoked while $35(19.4 \%)$ participants reported to smoke at home. Thirty one (17.2\%) participants acknowledged that they were not able continue work in the absence of smoking. Though, only 21 (11.7\%) of them were found to be addicted with smoking.

Twenty nine participants (16.1\%) were unable to quit smoking ever and hence found to have lack of will power. Seventeen (9.4\%) participants were not getting their promotion on time and $23(12.8 \%)$ had no due salary increment. Sixteen $(8.9 \%)$ ensued lack of incentive in their organization. (Table 1)

Table 1. Shows the frequency of different variables among the sample population

\begin{tabular}{|c|c|c|c|}
\hline & & Frequency & Percent \\
\hline \multirow[t]{2}{*}{ Gender } & male & 116 & 64.4 \\
\hline & female & 64 & 35.6 \\
\hline \multirow[t]{3}{*}{ Hospital/Institute } & DUHS & 128 & 71.1 \\
\hline & Shifa & 21 & 11.7 \\
\hline & liaquat & 31 & 17.2 \\
\hline \multirow[t]{3}{*}{ Type of Health care provider } & doctor & 43 & 23.9 \\
\hline & nurse & 67 & 37.2 \\
\hline & technician & 70 & 38.9 \\
\hline \multirow[t]{2}{*}{ Department } & medicine & 99 & 55 \\
\hline & surgery & 81 & 45 \\
\hline \multirow[t]{2}{*}{ Are you a smoker for the past one year? } & yes & 52 & 28.9 \\
\hline & no & 128 & 71.1 \\
\hline \multirow{2}{*}{$\begin{array}{l}\text { Number of cigarettes that you smoke per } \\
\text { day }\end{array}$} & less than 5 & 31 & 59.6 \\
\hline & more than 5 & 21 & 40.4 \\
\hline \multirow{2}{*}{$\begin{array}{l}\text { How many of your friends or colleagues } \\
\text { smoke? }\end{array}$} & less than $50 \%$ & 30 & 57.7 \\
\hline & more than $50 \%$ & 22 & 42.3 \\
\hline
\end{tabular}




\begin{tabular}{|c|c|c|c|}
\hline \multirow{2}{*}{$\begin{array}{l}\text { How many hours do you spend in the } \\
\text { company of your smoker friends? }\end{array}$} & less than $6 \mathrm{hrs}$ & 30 & 57.7 \\
\hline & more than $6 \mathrm{hrs}$ & 22 & 42.3 \\
\hline \multirow[t]{2}{*}{ Influence of friends and peer pressure } & Not Influenced & 32 & 61.5 \\
\hline & Influenced & 20 & 38.5 \\
\hline \multirow[t]{2}{*}{ Do you smoke at work place? } & no & 18 & 34.6 \\
\hline & yes & 34 & 65.4 \\
\hline \multirow[t]{2}{*}{ Do you smoke at home? } & no & 17 & 32.7 \\
\hline & yes & 35 & 67.3 \\
\hline \multirow{2}{*}{$\begin{array}{l}\text { Are you able to continue routine work in the } \\
\text { absence of smoking? }\end{array}$} & yes & 21 & 40.4 \\
\hline & no & 31 & 59.6 \\
\hline \multirow[t]{2}{*}{ Addiction } & Not Addicted & 31 & 59.6 \\
\hline & Addicted & 21 & 40.4 \\
\hline \multirow[t]{2}{*}{ Lack of will power } & no & 23 & 44.2 \\
\hline & yes & 29 & 55.8 \\
\hline \multirow[t]{2}{*}{ Are you getting your promotion on time? } & yes & 35 & 67.3 \\
\hline & no & 17 & 32.7 \\
\hline \multirow{2}{*}{$\begin{array}{l}\text { Are you getting your due increment in } \\
\text { salary? }\end{array}$} & yes & 29 & 55.8 \\
\hline & no & 23 & 44.2 \\
\hline \multirow[t]{2}{*}{ Lack of incentive } & No & 36 & 69.2 \\
\hline & Yes & 16 & 30.8 \\
\hline
\end{tabular}

There was no leading significant effect of demographic variables on smoking habit and influencing factor for the same. (Table 2)

Table 2. Depicts the effect of demographic variables on smoking habit

\begin{tabular}{|c|c|c|c|c|c|c|c|c|c|c|c|c|c|c|c|}
\hline & & \multicolumn{2}{|l|}{ Gender } & \multirow{2}{*}{ P Value } & \multicolumn{3}{|c|}{ Hospital/Institute } & \multirow{2}{*}{ P Value } & \multicolumn{3}{|c|}{ Type of Health care provider } & \multirow{2}{*}{ P Value } & \multicolumn{2}{|c|}{ Department } & \multirow{2}{*}{ P Value } \\
\hline & & male & female & & DUHS & Shifa & liaquat & & doctor & nurse & technician & & medicine & surgery & \\
\hline \multirow{4}{*}{$\begin{array}{l}\text { Are you a } \\
\text { smoker for } \\
\text { the past one } \\
\text { year? }\end{array}$} & \multirow{2}{*}{ yes } & 45 & 7 & \multirow{4}{*}{$<0.001$} & 32 & 12 & 8 & \multirow{4}{*}{0.0098} & 11 & 17 & 24 & \multirow{4}{*}{0.444} & 30 & 22 & \multirow{4}{*}{0.78} \\
\hline & & $86.54 \%$ & $13.20 \%$ & & $60.40 \%$ & $22.60 \%$ & $15.38 \%$ & & $20.80 \%$ & $32.10 \%$ & $46.15 \%$ & & $56.60 \%$ & $42.31 \%$ & \\
\hline & \multirow{2}{*}{ No } & 71 & 57 & & 96 & 9 & 23 & & 32 & 50 & 46 & & 69 & 59 & \\
\hline & & $55.47 \%$ & $44.90 \%$ & & $75 \%$ & $7.10 \%$ & $17.97 \%$ & & $25.20 \%$ & $39.40 \%$ & $35.94 \%$ & & $54.30 \%$ & $46.09 \%$ & \\
\hline \multirow{4}{*}{$\begin{array}{l}\text { Number of } \\
\text { cigarettes } \\
\text { that you } \\
\text { smoke per } \\
\text { day }\end{array}$} & \multirow{2}{*}{ less than 5} & 24 & 7 & \multirow{4}{*}{0.033} & 22 & 3 & 6 & & 5 & 11 & 15 & \multirow{4}{*}{0.554} & 18 & 13 & \multirow{4}{*}{0.947} \\
\hline & & $77.40 \%$ & $22.60 \%$ & & $71.00 \%$ & $9.70 \%$ & $19.40 \%$ & & $16.10 \%$ & $35.50 \%$ & $48.40 \%$ & & $58.10 \%$ & $41.90 \%$ & \\
\hline & more than & 21 & 0 & & 10 & 9 & 2 & & 6 & 6 & 9 & & 12 & 9 & \\
\hline & 5 & $100.00 \%$ & $0.00 \%$ & & $47.60 \%$ & $42.90 \%$ & $9.50 \%$ & & $28.60 \%$ & $28.60 \%$ & $42.90 \%$ & & $57.10 \%$ & $42.90 \%$ & \\
\hline \multirow{4}{*}{$\begin{array}{l}\text { Influence of } \\
\text { friends and } \\
\text { peer } \\
\text { pressure }\end{array}$} & Not & 25 & 7 & \multirow{4}{*}{0.035} & 26 & 0 & 6 & & 7 & 10 & 15 & \multirow{4}{*}{0.959} & 18 & 14 & \multirow{4}{*}{0.79} \\
\hline & Influenced & $78.10 \%$ & $21.90 \%$ & & $81.30 \%$ & $0.00 \%$ & $18.80 \%$ & & $21.90 \%$ & $31.30 \%$ & $46.90 \%$ & & $56.30 \%$ & $43.80 \%$ & \\
\hline & \multirow{2}{*}{ Influenced } & 20 & 0 & & 6 & 12 & 2 & & 4 & 7 & 9 & & 12 & 8 & \\
\hline & & $100.00 \%$ & $0.00 \%$ & & $30.00 \%$ & $60.00 \%$ & $10.00 \%$ & & $20.00 \%$ & $35.00 \%$ & $45.00 \%$ & & $60.00 \%$ & $40.00 \%$ & \\
\hline \multirow{4}{*}{ Addiction } & Not & 25 & 6 & & 23 & 3 & 5 & & 5 & 9 & 17 & & 21 & 10 & \\
\hline & Addicted & $80.60 \%$ & $19.40 \%$ & \multirow{3}{*}{0.219} & $74.20 \%$ & $9.70 \%$ & $16.10 \%$ & & $16.10 \%$ & $29.00 \%$ & $54.80 \%$ & \multirow{3}{*}{0.289} & $67.70 \%$ & $32.30 \%$ & 0075 \\
\hline & & 20 & 1 & & 9 & 9 & 3 & & 6 & 8 & 7 & & 9 & 12 & 0.018 \\
\hline & 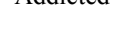 & $95.20 \%$ & $4.80 \%$ & & $42.90 \%$ & $42.90 \%$ & $14.30 \%$ & & $28.60 \%$ & $38.10 \%$ & $33.30 \%$ & & $42.90 \%$ & $57.10 \%$ & \\
\hline & $\mathrm{No}$ & 19 & 4 & & 16 & 3 & 4 & & 7 & 5 & 11 & & 12 & 11 & \\
\hline Lack of will & 10 & $82.60 \%$ & $17.40 \%$ & 0.686 & $69.60 \%$ & $13.00 \%$ & $17.40 \%$ & & $30.40 \%$ & $21.70 \%$ & $47.80 \%$ & & $52.20 \%$ & $47.80 \%$ & \\
\hline power & & 26 & 3 & 0.000 & 16 & 9 & 4 & & 4 & 12 & 13 & & 18 & 11 & \\
\hline & $y 00$ & $89.70 \%$ & $10.30 \%$ & & $55.20 \%$ & $31.00 \%$ & $13.80 \%$ & & $13.80 \%$ & $41.40 \%$ & $44.80 \%$ & & $62.10 \%$ & $37.90 \%$ & \\
\hline & $\mathrm{No}$ & 33 & 3 & & 20 & 10 & 6 & & 9 & 13 & 14 & & 20 & 16 & \\
\hline Lack of & No & $91.70 \%$ & $8.30 \%$ & 0.182 & $55.60 \%$ & $27.80 \%$ & $16.70 \%$ & & $25.00 \%$ & $36.10 \%$ & $38.90 \%$ & 0.276 & $55.60 \%$ & $44.40 \%$ & 0.64 \\
\hline incentive & Ye & 12 & 4 & 0.102 & 12 & 2 & 2 & & 2 & 4 & 10 & 0.210 & 10 & 6 & (1) \\
\hline & 160 & $75.00 \%$ & $25.00 \%$ & & $75.00 \%$ & $12.50 \%$ & $12.50 \%$ & & $12.50 \%$ & $25.00 \%$ & $62.50 \%$ & & $62.50 \%$ & $37.50 \%$ & \\
\hline
\end{tabular}


It was found that those who were influenced by their peers were 8.33 times more prone to be addicted to smoking than those who were less influenced. Similarly, the likelihood of addiction increased up to $76.9 \%$ with the lack of incentives causes. None of the other factors were significantly associated with each other. (Table 3 )

Table 3. Shows the relation between peer pressure, addiction, lack of will power and incentive

\begin{tabular}{|c|c|c|c|c|c|c|c|c|c|c|}
\hline & & \multicolumn{2}{|l|}{ Addiction } & \multirow{2}{*}{ P Value } & \multicolumn{2}{|c|}{ Lack of will power } & \multirow{2}{*}{ P Value } & \multicolumn{2}{|c|}{ Lack of incentive } & \multirow{2}{*}{ P Value } \\
\hline & & Not Addicted & Addicted & & no & yes & & No & Yes & \\
\hline \multirow{4}{*}{$\begin{array}{l}\text { Influence of } \\
\text { friends and } \\
\text { peer pressure }\end{array}$} & \multirow{2}{*}{$\begin{array}{l}\text { Not } \\
\text { Influenced }\end{array}$} & 25 & 7 & 0.001 & 16 & 16 & 0.289 & 21 & 11 & 0.476 \\
\hline & & $78.10 \%$ & $21.90 \%$ & $\mathrm{OR}=8.33$ & $50.00 \%$ & $50.00 \%$ & $\mathrm{OR}=1.86$ & $65.60 \%$ & $34.40 \%$ & $\mathrm{OR}=0.64$ \\
\hline & \multirow{2}{*}{ Influenced } & 6 & 14 & (95\%CI: & 7 & 13 & (95\%CI: & 15 & 5 & (95\%CI: \\
\hline & & $30.00 \%$ & $70.00 \%$ & 2.34-29.72) & $35.00 \%$ & $65.00 \%$ & $0.59-5.87)$ & $75.00 \%$ & $25.00 \%$ & $0.18-2.22)$ \\
\hline \multirow{4}{*}{ Addiction } & Not & & & & 13 & 18 & 0.686 & 18 & 13 & 0.034 \\
\hline & Addicted & & & & $41.90 \%$ & $58.10 \%$ & $\mathrm{OR}=0.79$ & $58.10 \%$ & $41.90 \%$ & $\mathrm{OR}=0.23$ \\
\hline & \multirow{2}{*}{ Addicted } & & & & 10 & 11 & (95\%CI: & 18 & 3 & (95\%CI: \\
\hline & & & & & $47.60 \%$ & $52.40 \%$ & $0.26-2.42)$ & $85.70 \%$ & $14.30 \%$ & 0.06-0.95) \\
\hline \multirow{4}{*}{$\begin{array}{l}\text { Lack of will } \\
\text { power }\end{array}$} & \multirow{2}{*}{ no } & & & & & & & 17 & 6 & 0.515 \\
\hline & & & & & & & & $73.90 \%$ & $26.10 \%$ & $\mathrm{OR}=1.49$ \\
\hline & \multirow{2}{*}{ yes } & & & & & & & 19 & 10 & (95\% $\mathrm{CI}:$ \\
\hline & & & & & & & & $65.50 \%$ & $34.50 \%$ & $0.45-4.98)$ \\
\hline
\end{tabular}

\section{Discussion}

In Lahore, Pakistan the average total prevalence of smoking amongst health care providers, which includes doctors and paramedic staff, is $37.18 \%$ and $35.74 \%$ respectively with a male to female gender prevalence being $50.31 \%$ to $7.04 \%$ amongst doctors and $61.53 \%$ to $2.22 \%$ amongst paramedic staff (Malick et al., 2010). In a research carried out in the neighboring country of Pakistan (China), amongst all the respondents sampled, 20.8\% were found to be current smokers who represented about $35.7 \%$ of the physician doctors and $1.4 \%$ of the nurses (Yan et al., 2008). This is in comparison to our research which establishes that out of the 180 people sampled, $28.9 \%$ people smoked with $25 \%$ being male smokers and only $3.9 \%$ being female smokers. Thus it can be stated that our data follows the regional trend, as per the gender aspect, showing a low frequency of female health care provider smokers and a moderate to high frequency of male smokers in our part of the region of Asia. This, as opposed to Italy which shows a higher percentage of smoking amid the female members, $41 \%$ of the hospital staff as compared to males (Zanetti et al., 1998). However, the exact reason for such a region wise change is yet unknown. Our research also shows an increasing trend of smoking from doctors $(6.1 \%)$ to nurses $(9.4 \%)$ and technicians (13.9\%) which is opposed to a research in China which shows a high prevalence of smoking amongst doctors and a low prevalence amongst nurses (Yan et al., 2008). The lower level of smoking amongst doctors, as indicated by our research, is supported by a research in Poland (Cofta \& Staszewski, 2008).

Of the total people who do smoke, our research established that $40.4 \%$ of the people smoked more than 5 cigarettes per day. This is consistent with the Pakistani trend supported by the fact that about $26.44 \%$ doctors and $41.89 \%$ paramedics smoked 11-20 cigarettes a day (Malick et al., 2010). Furthermore, $65.4 \%$ of smokers also smoked in their work place. Therefore, it can be stated that of the hospital staff who smoke, a much significant proportion are more prone towards smoking in their work place, which could be a representative measure of the level of addiction and tolerance .Our research also laid down strong association of smoking with peer pressure and the attitude of friends as shown by the fact that of the total people who smoked, $42.3 \%$ had more than $50 \%$ friends who smoked and spent more than 6 hours in the presence of their smoking friend company. This is supported by a number of researches at both, medical student and hospital level. In fact a research established an independent association of smoking and peer pressure amongst medical students (Ganesh Kumar, Subba, Unnikrishna, Jain, \& Badiger, 2011) and another research highlighted its strong role amongst $14-17$ year old teenagers (Husain et al., 2012). This is further pressed upon by a research which found the role of peer pressure in smoking in $83.6 \%$ of the future physicians out of which $42 \%$ had addictions and was one of the most 
important risk factor (57.69\%) for the initiation of the habit of smoking (Basu et al., 2011). The dominating role of peer pressure was also a strong determinant amongst doctors and paramedic staff, supported by a research which stated that $55.17 \%$ doctors and $75.68 \%$ paramedics started smoking under influence of friends. This is further supported by a research which found that $31 \%$ of the hospital staff was smoking under influence of peer pressure (Chaudhry, Chaudhry, \& Mamood, 2009). Association of peer pressure with smoking is following an increasing trend and therefore a strong relationship between peers' habbitsand an individual susceptibility towards smoking exists. Therefore steps taken to reduce peer pressure can significantly help reduce the incidence of smoking. In terms of the level of addiction, our data reveals a high level of addiction shown by the fact that of the total people who smoked, $65.4 \%$ smoked at the work place which includes hospitals. This can be used as an indicator showing the level of addiction amongst hospital staff which is further supported by the fact that $59.6 \%$ of the people couldn't carry out their routine work without smoking. Therefore, it is vital that important steps must be taken to make hospitals completely smoke free to aid healing of patients.

The exact cause of smoking is debatable but our statistics demonstrated that inadequate salaries and lack of promotion opportunities may also have a role in smoking. The reason that could be hypothesized is that such factors play a role in up regulating the level of anxiety amongst health care providers who then resort to smoking initially as an escape and then end up in being addicted. In a developing country like Pakistan, reasons other than monetary issues like political instability and violence could be amongst contributing factors towards smoking. Other perpetuating factors could be increased workload, which may be both psycho-social and physical in nature (Zysnarska, Bernad, Adamek, \& Maksymiuk, 2008). It is therefore important that such issues must be solved at both hospital and government level so as to ensure and maintain appropriate levels of hospital functioning which would ultimately aid the patient's needs. It can also be hypothesized that if such factors are overlooked, they could yield devastating results in future, with the health care providers then resorting to more harmful substances of abuse and eventually culminating in disaster of the profession.

The moderately high prevalence of smoking amongst health care providers is alarming as they are setting a bad example to patients by being uncritical to this habit by rarely asking patients about their smoking and rarely advising them not to smoke (Stojanović et al., 2013). This is further elaborated by a research which found out that of the physicians who smoke, $25 \%$ do not warn their patients about the risks of smoking and about $22 \%$ not always give advice to them about quitting (Araya et al., 2012). Therefore strong steps must be taken to decrease it amongst health care providers to indirectly reduce its prevalence in the general population. This could be achieved by early identification of smokers. Therefore researches like these must be carried out at medical school level to identify smokers at an early stage. Schools must devise rules and policiesto discourage smoking (Ghimire, Sharma, Niraula, Devkota, \& Pradhan, 2013). The exact causes of smoking must be identified and then eradicated. The government can also play its part by imposing heavy taxation on cigarette to limit its availability and restricting cigarette advertisements. Moreover, motivation by friends and family members could also help. Other researches so as to percept the risk of smoking amongst the general population and health care providers could also be carried out (Power, Neilson, \& Perry, 2004). Important steps must be taken so as to promote smoke free environmental policies as it could help reduce the levels of smoking in hospitals and also amongst hospital staff as supported by a research which shows that after such implementations the level of smoking in staff could be reduced by $44 \%$ in a 2 year period (Poder, Carroll, Wallace, \& Hua, 2012). In fact the ban on smoking in public places has shown that amongst nurses $68 \%$ had decreased their tobacco consumption in their working hours and about $28 \%$ had reduced their overall daily consumption (Maurel-Donnarel, Baumstarck-Barrau, Barlesi, \& Lehucher-Michel, 2010). To our knowledge this is amongst the few researches which cover such an important aspect in our region.

Our research only focused on doctors, nurses and technicians.It should be noted, however, that inclusion of other members of paramedic staff and dentists in the sample population may have given a better picture.

The doctors could have been further subdivided according to the departments, so as to highlight the department which is involved more in smoking. The sample size of 180 people was very small and couldhave been increased by including more tertiary care hospitals. An increase in sample size increases the reliability of study and the study becomes more representative of the targeted population. A much more validated scale for the measurement of addiction and stress like the Fagerstorm Test could have been used to make the results more valid and consistent. Much more detailed correlates to the multiple causes of smoking, other than stress and promotion, could have been pinpointed so as to identify the correct and exact cause. Furthermore it could have been of great use if attitude of doctors and paramedics towards smoking cessation was asked. 


\section{Conclusion}

Our results clearly indicate that a large number of health care providers smoke which should be a serious concern. We also found that addiction was significantly associated with lack of incentives and peer pressure. Hence our health agencies should take immediate action in order to curtail the heaving burden of smoking and its related health consequences.

\section{References}

Abdullah, A. S. M., \& Husten, C. G. (2004). Promotion of smoking cessation in developing countries: a framework for urgent public health interventions. Thorax, 59, 623-630. http://dx.doi.org/10.1136/thx.2003.018820

Araya, A. M. V., Leal, S. F., Huerta, G. P., Fernández, A. N., Fernández, O. G., \& Millones, E. J. P. (2012). The influence of smoking habits of Chilean physicians on the use of the structured medical advice about smoking. Rev Med Chil, 140(3), 347-52.

Asfar, T., Al-Ali, R., Ward, K. D., Vander Weg, M. W., \& Maziak, W. (2011). Are primary health care providers prepared to implement an anti-smoking program in Syria? Patient Educ Couns, 85(2), 201-5. http://dx.doi.org/10.1016/j.pec.2010.11.011

Basu, M., Das, P., Mitra, S., Ghosh, S., Pal, R., \& Bagchi, S. (2011). Role of family and peers in the initiation and continuationof smoking behavior of future physicians. J Pharm Bioallied Sci, 3(3), 407-11. http://dx.doi.org/10.4103/0975-7406.84452

Chaudhry, M. A., Chaudhry, I. A., \& Mamood. (2009). Prevalence of smoking among health care providers in tertiary care hospitals. Rawal Med J, 34(1), 40-2.

Cofta, S., \& Staszewski, R. (2008). Hospital staff and smoking habits: do we need modification of smoking behavior in Polish hospitals? J Physiol Pharmacol, 59(Suppl 6), 191-9.

Ganesh Kumar, S., Subba, S. H., Unnikrishna, B., Jain, A., \& Badiger, S. (2011). Prevalence and factor associated with current smoking among medical students in coastal South India. Kathmandu Univ Med $J$ (KUMJ), 9(36), 233-7.

Ghimire, A., Sharma, B., Niraula, S. R., Devkota, S., \& Pradhan, P. S. (2013). Smoking Habit among Male Medical and Dental Students of B.P.Koirala Institute of Health Sciences, Nepal. Kathmandu Univ Med J (KUMJ), 11(41), 32-6.

Global adult tobacco survey collaborative group. (2011). Tobacco questions for surveys: A subset of key questions from the global adult tobacco survey (GATS) (2nd Edition). Atlanta, GA: Centers of disease control and prevention.

Husain, M. O., Duddu, V., Husain, M., Drury, A., Chaudhry, N., \& Husain, N. (2012). Smoking behavior among 14-17 year old students: a comparison between Pakistan and the UK. Southeast Asian J Trop Med Public Health, 43(1), 219-28.

Malick, A. K., Chaudhry, A., Karamat, A., Arif, N., Cheema, M. A., \& Rauf, A. (2010). Cigarette smoking and health care professionals at Mayo hospital, Lahore, Pakistan. J Pak Med Assoc, 60(6), 509-12.

Maurel-Donnarel, E., Baumstarck-Barrau, K., Barlesi, F., \& Lehucher-Michel, M. P. (2010). The ban on smoking in public places (Decree No. 2006-1386 of 15th November 2006): Impact over 12 months onsmoking status of hospital nurses. Rev Mal Respir, 27(3), 199-212. http://dx.doi.org/10.1016/j.rmr.2010.01.007

Nawaz, A., \& Naqvi, S. A. S. (2008). Attitudes, perceptions, habits of smoker, Non-smoker general practitioners and why they fail to motivate patients to quit smoking. Pak J Med Sci, 24, 1152-56.

Poder, N., Carroll, T., Wallace, C., \& Hua, M. (2012). Do smoke-free environment policies reduce smoking on hospital grounds? Evaluation of a smoke-free health service policy at two Sydney hospitals. Aust Health Rev, 36(2), 158-62. http://dx.doi.org/10.1071/AH11998

Power, B., Neilson, S., \& Perry, I. J. (2004). Perception of the risks of smoking in the general population and among general practitioners in Ireland. Ir J Med Sci, 173(3), 141-4. http://dx.doi.org/10.1007/BF03167928

Serna, L., Bialuos, S. A., Sinha, K., Yang, Q., \& Wewers, M. E. (2010). Are Health care Providers Still Smoking? Data From the 2003 and 2006/2007 Tobacco Use Supplement-Current Population Surveys. Nicotine Tob Res, 12(11), 1167-1171. http://dx.doi.org/10.1093/ntr/ntq161

Stojanović, M., Musović, D., Petrović, B., Milosević, Z., Milosavljević, I., Visnjić, A., \& Sokolović, D. (2013). 
Smoking habits, knowledge about and attitudes toward smoking among employees in health institutions in Serbia. Vojnosanit Pregl, 70(5), 493-500. http://dx.doi.org/10.2298/VSP1305493S

Thomson, N. C., Chaudhuri, R., \& Livingston, E. (2004). Asthma and cigarette smoking. European Respiratory $J, 24,822-33$. http://dx.doi.org/10.1183/09031936.04.00039004

Yan, J., Xiao, S., Ouyang, D., Jiang, D., He, C., \& Yi, S. (2008). Smoking behavior, knowledge, attitudes and practices among health care providers in Changsha city, China. Nicotine Tob Res, 10(4), 737-44. http://dx.doi.org/10.1080/14622200801901930

Zanetti, F., Gambi, A., Bergamaschi, A., Gentilini, F., De Luca, G., Monti, C., \& Stampi, S. (1998). Smoking habits, exposure to passive smoking and attitudes to a non-smoking policy among hospital staff. Public Health, 112(1), 57-62. http://dx.doi.org/10.1038/sj.ph.1900419

Zysnarska, M., Bernad, D., Adamek, R., \& Maksymiuk, T. (2008). Tobacco smoking among nurses--a lack of knowledge or effect of work overload? Przegl Lek, 65(10), 602-4.

\section{Copyrights}

Copyright for this article is retained by the author(s), with first publication rights granted to the journal.

This is an open-access article distributed under the terms and conditions of the Creative Commons Attribution license (http://creativecommons.org/licenses/by/3.0/). 